\title{
Avaliação Institucional em uma universidade pública brasileira multicâmpus: processos e desafios na qualificação da gestão
}

\author{
Hilda Alberton de Carvalho \\ Oséias Santos de Oliveira \\ Isaura Alberton de Lima
}

Resumo: O artigo objetiva refletir sobre os processos que compõem a avaliação institucional de uma universidade multicâmpus e suas contribuições na melhoria da gestão. A pesquisa, de natureza qualitativa, tem sua abordagem centrada em um estudo de caso com foco em uma IES pública situada no Estado do Paraná/Brasil. O estudo parte das ações adotadas pela instituição no atendimento da legislação bem como de suas políticas internas de avaliação e os desdobramentos na gestão. As reflexões se pautam em uma análise documental com base na legislação nacional e nos documentos da universidade como o Relatório de Gestão e o Relatório de Autoavaliação Institucional, dentre outros, sendo essas associadas a uma pesquisa participante. As práticas avaliativas instituídas nos treze câmpus da IES permitem as seguintes conclusões: a) mudanças e inovações fazem parte da sociedade e a universidade atua como indutora dessas inovações, por meio do ensino, da pesquisa, da extensão e da gestão; b) vencer o desafio de crescer quantitativamente e qualitativamente passa pela definição de indicadores e de processos avaliativos consistentes; c) os progressos em torno da avaliação institucional possibilitam a melhoria da gestão universitária. Uma IES tecnológica com estrutura multicâmpus enfrenta desafios constantes que exigem decisões coletivas, planejamento e reorganização para que os objetivos da avaliação institucional sejam alcançados, em sintonia entre o macro contexto da universidade e as questões locais/regionais

Palavras-chave: Gestão universitária. Avaliação institucional. Universidade multicâmpus.

\section{Institutional assessment in a brazilian multi-campus public university: processes and challenges in management qualification}

Abstract: The article aims to reflect on the processes that make up the institutional assessment of a multi-campus university and its contributions in improving the management. The qualitative research has its approach centered on a case study focused on a public IES in the State of Paraná / Brazil. The study starts in the actions taken by the institution in compliance with legislation and internal assessment policies and developments in management. The reflections are guided on a documentary analysis based on the national legislation and university documents, such as the Management Report and the Institutional Self-Assessment Report, among others, being associated with a participant research. Assessment practices instituted in thirteen campus of IES allow the following conclusions: a) changes and innovations are part of society and the university acts as an inducer of these innovations, through teaching, research, extension and management; b) overcome the challenge of growing quantitatively and qualitatively goes through the definition of indicators and consistent assessment processes; c) progress around the institutional assessment allow improvement of university management. A technological IES with multi-campus structure faces constant challenges that require collective decisions, planning and reorganization so that the institutional assessment objectives are achieved aligned between the university's macro context and local / regional issues.

Key words: University management. Institutional assessment. Multi-campus university.

Este é um artigo publicado em acesso aberto sob uma licença Creative Commons

https://creativecommons.org/licenses/by-nc/4.0/ 


\section{Introdução}

Os processos que envolvem a avaliação institucional vêm sendo discutidos, nos diferentes níveis e etapas de educação, cada vez com maior amplitude em face das distintas possibilidades de organização e aplicação de princípios e práticas da gestão. Cabe salientar, inicialmente, que este artigo configura-se em uma versão revisada e ampliada de estudo desenvolvido por Carvalho, Oliveira e Lima (2016), intitulado "Contribuições da avaliação institucional na qualificação da gestão do ensino superior: o caso da Universidade Tecnológica Federal do Paraná”, apresentado no I Congresso Nacional de Mestrados Profissionais em Administração Pública, ocorrido na UTFPR/Curitiba, em 2016, e publicado nos anais do evento.

No presente artigo o foco de discussão volta-se à temática da avaliação institucional no contexto do ensino superior, sendo que o objetivo está delimitado em refletir sobre o conjunto de processos que compõem a avaliação institucional de uma universidade pública multicâmpus, de modo a compreender como esses contribuem para ampliação da qualidade da gestão.

A avaliação institucional constitui-se em uma prática em uso no campo das políticas universitárias que situa, entre seus propósitos a melhoria da qualidade do processo de ensinoaprendizagem, a qualificação da gestão universitária e a prestação de contas à comunidade. Frente a esses escopos as ações que envolvem a avaliação institucional incidem em novas definições, em especial quanto ao campo de planejamento, notadamente no que se refere aos aspectos pedagógicos, administrativos, estruturais e financeiros, tanto das Instituições de Ensino Superior (IES) quanto dos sistemas de ensino aos quais estão vinculadas. Assim, destaca-se a necessidade de constantes reflexões e revisões sobre os processos avaliativos desenvolvidos, de modo que esses possam revelar a dimensão das demandas e ajustes necessários ao pleno desenvolvimento da educação superior.

A partir de uma abordagem qualitativa, pautada em um estudo de caso, busca-se analisar as práticas vivenciadas no contexto de uma IES pública brasileira, localizada no Estado do Paraná. Essa instituição adota o sistema de multicampia o que promove a inclusão socioeducacional de estudantes de treze regiões paranaenses. Entretanto, a descentralização provocada nesse modelo de universidade constitui-se em um desafio quanto a sua organização, gestão e processos de avaliação. A pesquisa documental (pautada na legislação nacional e em documentos próprios da IES analisada) alia-se a uma pesquisa participante, quando os autores, identificados com a temática em discussão, por sua atuação na área de avaliação institucional 
Avaliação Institucional em uma universidade pública brasileira multicâmpus: processos e desafios na qualificação da gestão

(como gestores ou integrantes da Comissão Própria de Avaliação), refletem sobre os processos avaliativos já consolidados e os desafios que se inserem em seu percurso de construção.

O entendimento das ações e práticas avaliativas desencadeadas no contexto da IES pesquisada exige uma análise mais detalhada dada a sua especificidade pautada no viés tecnológico e sua estrutura multicâmpus que se confirma por sua presença em praticamente todas as regiões do Estado do Paraná, o que requer que sejam consideradas as especificidades regionais de cada um de seus câmpus, sem perder de vista a unidade da instituição.

\section{Avaliação Institucional no Brasil: situando a base histórica de um processo em constante construção}

Em uma breve retrospectiva da construção do sistema de avaliação institucional das IES brasileiras é necessário situar, com base em estudos de Leite, Tutikian e Holtz (2000), que este processo se inicia, em 1977, com a avaliação dos programas de pós-graduação, pela Coordenação de Aperfeiçoamento do Pessoal de Nível Superior (CAPES). Na sequência, diversos estudos foram realizados com o objetivo de se pensar um sistema de avaliação institucional que contemplasse o conjunto das ações que constituem a base da universidade, pautadas no ensino, na pesquisa e na extensão.

A partir dos grupos de estudos constituídos para a discussão do sistema de avaliação institucional das IES brasileiras destacam-se, a seguir, as principais ações propostas em cada período. Nessa concisa retrospectiva busca-se perceber os desdobramentos das ações, em seus momentos históricos, e o alcance quanto ao delineamento das atuais políticas de avaliação institucional.

A Associação Nacional de Docentes (ANDES) propõe, em 1982, mediante estudos específicos, a avaliação institucional. A partir de então são promovidas discussões políticas importantes, como: a necessidade de colocar a universidade em um patamar de patrimônio social; a defesa da gratuidade do ensino, do padrão de qualidade unitário e, não menos importante, situa também o debate sobre a inserção social das atividades universitárias. Quanto ao padrão de qualidade projeta-se que esse deveria ser constatado por meio da avaliação das instituições e do trabalho docente, levando em consideração a história e condições reais de cada instituição (AMORIM, 1992).

Em 1983 surge, no contexto do Conselho de Reitores das Universidades Brasileiras (CRUB), o Programa de Avaliação de Reforma Universitária (PARU), notadamente caracterizado como um estudo, em âmbito nacional, sobre a gestão das universidades brasileiras. Almeida Júnior (2004) analisa que o PARU foi apresentado como um instrumento 
para subsidiar e diagnosticar a origem da crise das universidades brasileiras de modo a apontar caminhos para sua superação. Porém, o programa elaborado tem curta duração (sendo extinto em 1984) e não apresenta caminhos para formulação de normas legais e técnicas para o processo de avaliação das IES, o que torna essa proposta enfraquecida. As principais discussões suscitadas no contexto do PARU estiveram pautadas em temas como: a democratização da gestão; o acesso ao ensino superior por parte de diferentes segmentos da sociedade; as funções que as universidades desempenham na sociedade (formação de profissionais, produção e disseminação de conhecimentos). Esses temas são expressos nas áreas e subáreas temáticas para o estudo e debate, definidas no documento do Programa, a saber: área 1) Gestão das instituições: Poder e tomada de decisão; Administração acadêmica; Administração financeira e financiamento; Política de pessoal; área 2) Produção e disseminação do conhecimento: Ensino e pesquisa nas instituições de ensino superior; Interação entre instituições de ensino superior e comunidade (PARU, 1983 apud ALMEIDA JÚNIOR, 2004).

Uma comissão de notáveis, formada por professores universitários, professores do $1^{\circ} \mathrm{e}$ do $2^{\circ}$ Graus, personalidades do setor produtivo, do meio sindical e de entidades estudantis, foi incumbida, em 1985, de apresentar subsídios à formulação de uma nova política para a educação superior brasileira, sendo que para tal intento passa-se a realizar consultas à sociedade, com especial direcionamento à comunidade universitária. Essa comissão entrega, em novembro do mesmo ano, ao Ministério da Educação, o relatório intitulado "Uma Nova Política para a Educação Superior”. Nesse documento a falta de parâmetros para que o governo apresente uma política racional de alocação de recursos públicos com vistas ao fortalecimento das melhores instituições e indução das demais ao aperfeiçoamento é destacada como um dos mais graves problemas do ensino superior brasileiro. O relatório também recomenda que a avaliação do ensino superior seja concretizada com base nas seguintes dimensões: "avaliação dos cursos, avaliação dos alunos; avaliação dos professores; avaliação didático-pedagógica do ensino; avaliação de servidores técnicos e administrativos; e avaliação das carreiras" (ZAINKO, 2008, p. 828).

No ano de 1986 o Ministério da Educação (MEC) cria um novo grupo denominado Grupo Executivo para a Reformulação do Ensino Superior (GERES), uma vez que as expectativas do Estado não são plenamente contempladas, quando da elaboração do PARU, em especial no que refere-se a forma de controle da educação superior. Assim, o GERES apresenta uma proposta com base em uma mudança operacional, a qual desencadeou várias discussões acadêmicas capitaneadas pela ANDES e pelo CRUB, gerando projetos substitutivos. Como resultado nasceram três propostas, sendo: a) Proposta do Governo: pautada na avaliação com a 
Avaliação Institucional em uma universidade pública brasileira multicâmpus: processos e desafios na qualificação da gestão

participação da comunidade; b) Proposta da ANDES: centrada nos mecanismos democráticos, transparentes e legítimos de avaliação sistemática de atividades e c) Proposta do Conselho de Reitores de Universidades Brasileiras: unindo autonomia e avaliação em um processo aberto, de conhecimento público, inclusive com avaliação de desempenho (OLIVIEN et al., 1987 apud LEITE; TUTIKIAN; HOLZ, 2000).

Na sequência, em 1988, o MEC estuda a avaliação de custos das Instituições Federais de Ensino Superior (IFES), criando, por meio da Portaria 278/MEC/SESu a Comissão de Apropriação de Custos das IFES. A partir dos estudos efetivados pela comissão a Secretaria de Educação Superior do Ministério da Educação (SESu/MEC) desenvolveu um programa voltado à avaliação gerencial das IFES, cuja metodologia permitiu a coleta dados referentes ao desempenho gerencial das instituições e a transformação desses em indicadores que pudessem favorecer a tomada de decisão e consequentemente a melhoria da gestão (PESSOA; PETER; COCHRANE, 2001). No ano seguinte (1989) ocorre um amplo debate da avaliação com a realização, em Brasília, do Seminário Institucional Evaluation in Higher Education, com o apoio do British Concil. Paralelamente, diversas IES começam a organizar seus próprios processos de avaliação institucional (LEITE; TUTIKIAN; HOLTZ, 2000).

No ano de 1993 a Comissão Nacional de Avaliação elabora a proposta de Avaliação Institucional, que é oficializado com o nome de Programa Nacional de Avaliação Institucional das Universidades Brasileiras (PAIUB). Esse programa, que se origina das bases universitárias, a partir das discussões efetivadas no âmbito dos representantes dos reitores das universidades federais, associações de universidades estaduais e municipais, particulares e confessionais e de um comitê formado por representantes indicados, configurou-se, desde a sua criação, pelo mérito do diálogo entre o Estado e as IES. O PAIUB estabeleceu três fases centrais para o processo a ser desenvolvido pelas universidades, situados em: a) Avaliação Interna (autoavaliação), a partir de seus segmentos constitutivos, b) Avaliação Externa, por experts das áreas do conhecimento e/ou provedores de informações da comunidade externa e c) Reavaliação, que reúne e discute os resultados das avaliações anteriores, definindo ações para a melhoria da qualidade dos cursos, o repensar do Projeto Pedagógico e o Plano de Desenvolvimento da IES (LEITE; TUTIKIAN; HOLTZ, 2000).

Todos esses movimentos, pautados na articulação de grupos da sociedade, IES e Governo resultam na criação, em 2003, da Comissão Especial de Avaliação (CEA), na qual são realizadas discussões com a comunidade acadêmica e com a sociedade civil organizada, sendo produzido o documento intitulado "SINAES: bases para uma nova proposta de avaliação da 
educação superior". O Sistema de Avaliação da Educação Superior Brasileiro (SINAES) é estabelecido na Lei 1.086/04, de 14 de abril de 2004.

\subsection{O SINAES - desdobramentos sobre as atuais políticas de avaliação das Instituições de Ensino Superior}

Em uma observação dos percursos da avaliação das universidades federais no Brasil pode-se dizer que, a partir dos anos de 1990, esse foco torna-se condição essencial para os processos de gestão da Educação Superior. Segundo Souza e Silva (2014) expressões como eficiência e produtividade são conceitos presentes nos contextos das universidades. As alterações substantivas nos padrões de eficiência da gestão e na produção do trabalho acadêmico acabam ganhando centralidade a partir desse período, o que, na visão de Catani, Oliveira e Dourado (2004) efetivam-se mediante formulações políticas e teóricas e a partir de ações concretas de planejamento estratégico, pautado em um processo de remodelação organizacional, sob perspectivas diferenciadas.

Sob a análise desses autores ainda ratifica-se que: "em que pesem as diferentes posições políticos-ideológicas presentes nos debates, começam a ocorrer mudanças organizacionais com desenvolvimento das universidades, no sentido de torná-las mais ágeis, eficientes e produtivas" (CATANI; OLIVEIRA; DOURADO, 2004, p. 252, com grifos nossos).

$\mathrm{O}$ arcabouço legal sobre o qual fundamentam-se as atuais ações de planejamento, avaliação e remodelação organizacional das IES brasileiras situa-se a partir da Lei de Diretrizes e Bases da Educação Nacional (LDB) nº 9.394, de 20 de dezembro de 1996. Em especial, o disposto no artigo $9^{\circ}$ da referida lei, passa a tratar das incumbências da União inserido, entre elas, que esse ente federado tem o dever de baixar normas gerais para os cursos de graduação e pós-graduação, assegurar processo nacional de avaliação das instituições de educação superior, autorizar, reconhecer, credenciar, supervisionar e avaliar, respectivamente, os cursos das instituições de educação superior e os estabelecimentos do seu sistema de ensino. Ainda, em seu artigo 46, a LDB/96 preconiza prazos para os processos de autorização e o reconhecimento de cursos, bem como o credenciamento de instituições de educação superior, quando esses devem ser, renovados, periodicamente, após processo regular de avaliação (BRASIL, 1996). Tais encargos serão tratados em Diplomas Normativos apropriados, com vistas a sua operacionalização.

Ainda, outros importantes documentos normativos são propostos para a consolidação dos processos de avaliação das IES, o que podem ser identificados, como já mencionado, na Lei $n^{\circ} 10.861$, de 14 de abril de 2004, que cria o SINAES, bem como no Decreto $n^{\circ} 5.773$, de 
Avaliação Institucional em uma universidade pública brasileira multicâmpus: processos e desafios na qualificação da gestão

9 de maio de 2006 o qual dispõe sobre o exercício das funções de regulação, supervisão e avaliação de instituições de educação superior e cursos superiores de graduação e sequenciais no sistema federal de ensino.

O SINAES surge para atender aos dispositivos estabelecidos na LDB/96 e tem como objetivo assegurar processo nacional de avaliação das instituições de educação superior, dos cursos de graduação e do desempenho acadêmico de seus estudantes. Conforme já referenciado, o artigo $1^{\circ}$ da Lei $n^{\circ} 10.861 / 2004$ anuncia a finalidade principal do SINAES que se pauta pela melhoria da qualidade da Educação Superior, quando para isso deve-se concentrar esforços no sentido de expandir sua oferta, ampliar a eficácia das instituições e a efetividade acadêmica. De maneira especial, isso tudo necessita ser calcado em ações que promovam o compromisso e responsabilidade social das IES “por meio da valorização de sua missão pública, da promoção dos valores democráticos, do respeito à diferença e à diversidade, da afirmação da autonomia e da identidade institucional" (BRASIL, 2004).

O Decreto ${ }^{\circ} 5.773 / 2006$, em seu Art. $1^{\circ}, \S 3^{\circ}$ insere que a avaliação realizada no âmbito do SINAES “constituirá referencial básico para os processos de regulação e supervisão da educação superior, a fim de promover a melhoria de sua qualidade" (BRASIL, 2006). E, ainda, atribui, no Art. $3^{\circ}$, as competências para as funções de regulação, supervisão e avaliação ao Ministério da Educação, ao Conselho Nacional de Educação (CNE), ao Instituto Nacional de Estudos e Pesquisas Educacionais Anísio Teixeira (INEP) e à Comissão Nacional de Avaliação da Educação Superior (CONAES) (BRASIL, 2006).

As delimitações apresentadas nos Diplomas Normativos aqui referidos são decisivas para a consolidação do atual sistema de avaliação das IES e dos cursos superiores por essas ofertados. Assim, o sistema de avaliação executado pelo INEP é composto por três processos que compreendem: 1) a avaliação institucional; 2) a avaliação de curso; 3) a avaliação de desempenho dos estudantes (configurado no Exame Nacional de Desempenho de Estudantes ENADE). A partir da materialização desse tripé avaliativo pode-se conhecer e atuar com vistas a melhoria da qualidade das IES brasileiras e dos cursos por elas ofertados.

No Quadro 01 estão expostas as principais representações em torno de cada um dos processos que envolvem a avaliação da educação superior a partir do sistema de avaliação brasileiro. 


\section{Quadro 01 - Processos de avaliação da educação superior, responsáveis e características principais}

\begin{tabular}{|c|c|c|}
\hline $\begin{array}{c}\text { PROCESSOS DE } \\
\text { AVALIAÇÃO }\end{array}$ & $\begin{array}{l}\text { RESPONSÁ- } \\
\text { BILIDADE }\end{array}$ & CARACTERÍSTICAS \\
\hline $\begin{array}{r}\text { Avaliação } \\
\text { Institucional }\end{array}$ & $\begin{array}{r}\text { A própria } \\
\text { IES }\end{array}$ & $\begin{array}{l}\text { Por meio da Avaliação Institucional possibilita-se o autoconhecimento } \\
\text { da IES quanto às ações que desenvolve em torno do ensino, da pesquisa } \\
\text { e da extensão. É esperado a participação ativa de todos nos processos } \\
\text { que compõem essa avaliação, quando então, professores, alunos, } \\
\text { técnicos administrativos e egressos assumem o protagonismo nessa } \\
\text { ação. Juntos, esses atores devem apontar os avanços e os desafios } \\
\text { persistentes na organização/gestão da instituição. Inicialmente o } \\
\text { SINAES trazia dez dimensões no processo de Avaliação Institucional, } \\
\text { contudo, em 2014, houve reformulação do instrumento e as dimensões } \\
\text { foram agrupadas em cinco eixos assim delimitados: 1) Planejamento e } \\
\text { Avaliação Institucional; 2) Desenvolvimento Institucional; 3) Políticas } \\
\text { Acadêmicas; 4) Políticas de Gestão; 5) Infraestrutura Física. O relatório } \\
\text { gerado, a partir da visita in loco da comissão de avaliação designada } \\
\text { pelo INEP, permite que a instituição possa fazer seu replanejamento } \\
\text { levando em conta as suas fortalezas e fragilidades. }\end{array}$ \\
\hline $\begin{array}{r}\text { Avaliação de } \\
\text { Cursos }\end{array}$ & MEC/INEP & $\begin{array}{l}\text { A Avaliação de Cursos ocorre a partir do preenchimento de formulário } \\
\text { online no e-Mec, quando um responsável alimenta o sistema com as } \\
\text { principais informações do curso. Essas, por sua vez, serão elementos } \\
\text { indispensáveis ao processo de visita de avaliadores designados pelo } \\
\text { INEP para a verificação in loco. O instrumento avaliativo é composto } \\
\text { por três dimensões sendo que a primeira se refere à organização } \\
\text { didático-pedagógica; a segunda ao corpo docente e tutorial e a terceira } \\
\text { à infraestrutura. Os relatórios gerados nesse processo trazem uma } \\
\text { contribuição significativa à discussão dos pontos de melhora e dos } \\
\text { aspectos relevantes do curso avaliado. }\end{array}$ \\
\hline $\begin{array}{r}\text { ENADE - } \\
\text { Exame } \\
\text { Nacional de } \\
\text { Desempenho } \\
\text { de } \\
\text { Estudantes }\end{array}$ & MEC/INEP & $\begin{array}{l}\text { O ENADE teve sua primeira aplicação em } 2004 \text { e tem por finalidade } \\
\text { avaliar o desempenho dos estudantes do Ensino Superior, } \\
\text { especificamente com relação aos conteúdos programáticos previstos } \\
\text { nas diretrizes curriculares dos cursos de graduação, às habilidades e às } \\
\text { competências adquiridas em sua formação. Os cursos participam do } \\
\text { processo de acordo com o ciclo avaliativo que ocorre a cada três anos, } \\
\text { sendo que tomam parte desse processo uma amostra selecionada de } \\
\text { estudantes do primeiro e do último ano dos cursos avaliados no período. } \\
\text { Para os formandos selecionados a participação no exame é obrigatória } \\
\text { sendo condição indispensável para a emissão do histórico escolar. Já os } \\
\text { estudantes não selecionados podem participar do processo de } \\
\text { avaliação, na condição de voluntários. }\end{array}$ \\
\hline
\end{tabular}

Fonte: Os autores (2016).

Diante da concisa retomada histórica da avaliação institucional cabe considerar que os processos articulados à avaliação das IES e de seus cursos propiciam uma oportunidade singular para inserir a temática da qualidade educacional na pauta de discussões das instituições, avançando para aspectos significativos como planejamento, democratização e eficiência da gestão acadêmica, dentre outros. Esse movimento possibilita que as IES possam repensar suas práticas tendo em vista o redimensionamento de suas estratégias e o alcance de seus objetivos, pautados pela qualidade. 
Avaliação Institucional em uma universidade pública brasileira multicâmpus: processos e desafios na qualificação da gestão

A qualidade educacional, conforme defendem Dias Sobrinho e Balsan (2005), ultrapassa as camadas técnicas e científicas alcançando os mais profundos e diversos sentidos filosóficos, sociais e políticos. Desse modo, o compromisso de cada um dos atores educacionais, em sua atuação na educação superior, precisa ser concebido a partir de uma concepção de responsabilidade que se enreda e se consolida na avaliação das instituições, dos cursos e dos estudantes. Tal responsabilidade passa pela compreensão de que acima de todas as questões relacionadas à avaliação situa-se a busca por uma gestão profissional que oportunize que as IES enfrentem os desafios impostos pelo sistema, regulado pelo viés financeiro e mercadológico, de modo mais sereno.

\section{Metodologia: abordagens na construção da pesquisa}

A metodologia adotada neste estudo parte de uma abordagem qualitativa centrada em um Estudo de Caso quando uma IES pública, localizada no Estado do Paraná/Brasil, é objeto de análise quanto à organização e aos encaminhamentos adotados para atendimento das demandas legais e estruturais em termos de suas políticas de avaliação.

Conforme reflete Minayo (2010) a abordagem qualitativa é a que se aplica no estudo de elementos e situações que envolvem a história, as relações, as representações, as crenças, as percepções/opiniões, os produtos das interpretações que os humanos fazem a respeito do modo como vivem, como constroem seus artefatos e a si mesmos, como sentem e como pensam. Ainda que possa ser usada para estudos de aglomerados de grandes dimensões "as abordagens qualitativas se conformam melhor a investigações de grupos e segmentos delimitados e focalizados, de histórias sociais sob a ótica dos atores, de relações e para análises de discursos e de documentos" (p. 57).

Quanto aos procedimentos técnicos optou-se pelo Estudo de Caso que é definido por Yin (2005, p. 32) como sendo "uma investigação empírica que investiga um fenômeno contemporâneo dentro de seu contexto da vida real". O objeto do estudo de caso situa-se em torno de uma análise profunda de uma determinada unidade de estudo e visa ao exame detalhado de um ambiente, de um sujeito ou de uma situação em particular (GODOY, 1995). Assim, o estudo de caso possibilita o entendimento de certos fenômenos, de modo que se explicite como e por que esses ocorrem a partir de um contexto e de condições específicas.

Este estudo utiliza-se da pesquisa documental, que segundo Gil (2008, p. 51) "vale-se de materiais que não receberam ainda tratamento de análise ou que ainda podem ser reelaborados de acordo com os objetivos da pesquisa". No desenvolvimento da pesquisa foram 
utilizados documentos definidos por Gil (2008) como sendo de primeira mão, ou seja, que ainda não haviam sido analisados e também documentos de segunda mão, que já haviam sido objeto de análise. $\mathrm{O}$ estudo foi realizado utilizando-se como instrumentos principais para coleta de dados os documentos produzidos no contexto da IES investigada e disponibilizados publicamente, sendo as principais fontes de pesquisa: o Projeto de Desenvolvimento Institucional (PDI), o Relatório de Gestão (RG), o Relatório de Autoavaliação Institucional, Relato Institucional, entre outros.

Ainda, o contexto de análise possibilitou que a pesquisa documental estivesse associada à uma observação participante. A articulação entre pesquisa documental e pesquisa participante permite que essas possam ser concebidas como técnicas complementares que podem subsidiar as reflexões de cunho qualitativo, ensejando a compreensão de fenômenos sociais mais complexos. Os pesquisadores, envolvidos em situações de planejamento e acompanhamento das políticas de avaliação institucional da IES, estabelecem uma relação entre os elementos teóricos, as demandas legais e as práticas vividas no espaço em estudo. Nesse sentido, a pesquisa participante se interpõe como um componente político que permite debater a importância do processo de investigação tendo por perspectiva a intervenção na realidade social (CHIZZOTTI, 2006).

Por conta de sua dimensão multicâmpus a IES pesquisada possui um sistema avaliativo cujo gerenciamento é realizado por comissões específicas, sendo o mesmo composto pelos seguintes processos de autoavaliação: a) Avaliação do Servidor, b) Avaliação do Docente pelo Discente, c) Avaliação dos Setores pelos Usuários Externos, d) Avaliação de Clima Organizacional, e) Relato Institucional e f) Relatório de Autoavaliação Institucional. As Avaliações de Curso e a avaliação do ENADE são operacionalizadas a partir de comissões externas, capitaneadas pelo MEC/INEP. Nesse estudo, o viés de análise recai sobre a avaliação que se opera no conjunto da autoavaliação, sem adentrar na discussão daquelas que se operam por meio do MEC/INEP (avaliação de cursos e ENADE).

\section{Desafios da Avaliação Institucional em uma universidade tecnológica multicâmpus}

Inúmeros desafios se interpõem a uma IES em seu processo de Avaliação Institucional. Em se tratando de uma IES tecnológica com estrutura multicâmpus esses desafios exigem uma série de ajustes, de decisões coletivas e, muitas vezes, reorganização para que os objetivos da avaliação institucional sejam alcançados, em consonância com o macro contexto da IES e as questões locais/regionais. 
Avaliação Institucional em uma universidade pública brasileira multicâmpus: processos e desafios na qualificação da gestão

A reflexão sobre os sentidos expressos em torno do conceito multicâmpus situa que esse pressupõe um modelo diferenciado de universidade, com características distintas da universidade tradicional. As marcações que diferenciam uma universidade multicâmpus ultrapassam a simples vinculação a uma IES com um número maior de câmpus, sobretudo, quando inserem as complexidades em torno de aspectos estruturais, acadêmicos, pedagógicos e de gestão (DELFRATE et al., 2008; FIALHO, 2005).

Ao discutir a missão de uma universidade de cunho tecnológico Schallemberger (2006), enfatiza que essa assenta-se na vocação de preparar indivíduos para liderar os processos produtivos e para a socialização de saberes, contudo, em nenhum momento a possível vocação tecnológica pode provocar a cisão entre inovação e tradição. Nesse sentido, como destaca Calado (1998), o papel da formação que se opera no contexto de uma IES, mesmo a de índole tecnológica, precisa ser focado na preparação do cidadão para resolver problemas complexos e novos, auxiliando-o no processo de pensar. Isso possibilita um avanço significativo em termos de transposição dos comportamentos estanques permitindo, também, o pensar e o ensinar, em termos transversais e profundos.

O significado multicâmpus para uma universidade tecnológica é discutido por Schallemberger (2006), que destaca a necessidade de se atentar para as especificidades regionais em articulação entre o saber científico e as complexidades do contexto onde se insere. O modelo multicâmpus favorece, na visão de Lauxen (2006), a interiorização da educação superior, uma vez que cada câmpus se torna, a certo modo, sede da universidade. Assim, uma IES multicâmpus precisa adotar características administrativas próprias que se operam na autonomia de recursos e nas particularidades acadêmico-científicas, de modo que cada unidade possa integrar-se ao todo e ao mesmo tempo relacionar-se, de modo intenso, com o contexto regional ao qual faz parte.

\subsection{O Estudo de Caso: situando o contexto da UTFPR - uma instituição centenária com uma política de avaliação institucional pioneira}

A Universidade Tecnológica Federal do Paraná (UTFPR) possui uma tradição referenciada em mais de 100 anos de história institucional, com ênfase na educação técnica, tecnológica e superior. Criada em 1910, como Escola de Aprendizes Artífices passou por diversas designações, conforme o enfoque de sua atuação. Assim, ocorre a transformação em Liceu Industrial do Paraná (em 1937), em Escola Técnica de Curitiba (em 1942), em Escola Técnica Federal do Paraná (em 1959) e em Centro Federal de Educação Tecnológica do Paraná - CEFET/PR (em 1978). O percurso de expansão com foco prioritário no ensino superior se 
desenha há pouco mais de uma década, quando a instituição, a partir de 2005, é transformada, por decreto presidencial, em um Instituição de Ensino Superior, sob a denominação de Universidade Tecnológica Federal do Paraná (UTFPR).

Em decorrência de um projeto de expansão articulado no âmbito federal, atualmente a IES está situada em diversas regiões do Estado do Paraná, constituindo-se em 13 câmpus, situados nas cidades de: Apucarana, Campo Mourão, Cornélio Procópio, Curitiba (articulado nas sedes Centro e Ecoville), Dois Vizinhos, Francisco Beltrão, Guarapuava, Londrina, Medianeira, Ponta Grossa, Pato Branco, Toledo e Santa Helena. A partir dessa ampla cobertura geográfica a IES passa a cumprir importante papel na oferta da educação pública e na indução do desenvolvimento regional e social, oferecendo ensino em diversos níveis e modalidades.

A relevância da presença da IES em praticamente todas as regiões do Estado do Paraná confirma-se frente ao número de estudantes atendidos e profissionais que atuam em seus cursos (técnicos, tecnologias, bacharelados, licenciaturas, especializações, mestrados e doutorados). Os dados extraídos do Relatório de Gestão (UTFPR, 2015a) revelam um contingente de 30.599 estudantes distribuídos em 305 cursos, de diferentes níveis/etapas, sendo a predominância estabelecida em torno de 75 cursos de bacharelados (com 17.569 alunos), seguido de 46 cursos superiores de tecnologias (com 3.549 alunos), de 18 licenciaturas (com 2.207 acadêmicos) e 19 cursos técnicos (com 971 estudantes). Em relação a pós-graduação a IES conta, nesse período, com 99 cursos de especialização (com 4.371 alunos), 41 cursos de mestrado (com 1.638 estudantes) e 7 cursos de doutorado (com 368 discentes).

A ênfase nos cursos de bacharelado pode ser percebida a partir da intensa mobilização na oferta de engenharias e tecnologias, que tiveram três grandes momentos para a graduação. O primeiro deles ocorreu ainda no final da década de 1970 com a implantação das três engenharias, mecânica, elétrica e eletrônica. O segundo marco ocorreu no final da década de 1990, quando no então CEFET/PR, ocorre a implantação dos cursos de tecnologias; e o terceiro momento, já como UTFPR, se delimita a partir de 2007 quando da implantação do projeto do Programa de Apoio a Planos de Reestruturação e Expansão das Universidades Federais (REUNI), cujo objetivo se fixou em criar condições para a ampliação do acesso e permanência na educação superior, no nível de graduação, pelo melhor aproveitamento da estrutura física e de recursos humanos existentes nas universidades federais.

No período mais recente, com a transformação em Universidade, observa-se a ampliação e a consolidação da pós-graduação no contexto da IES. Esse processo provoca forte impacto nos processos que envolvem a pesquisa, o ensino e a extensão. 
Avaliação Institucional em uma universidade pública brasileira multicâmpus: processos e desafios na qualificação da gestão

No que se refere à força de trabalho os indicadores institucionais revelam um total de 3.647 servidores efetivos, sendo 1.174 Técnicos-Administrativos (TAs) e, quanto a carreira docente, assim distribuídos: Docentes da Carreira de Educação Básica, Técnica e Tecnológica (EBTT): 1.008, Docentes do Magistério Superior: 1.464 e Livre Docente: 01, perfazendo um total de 2.473 docentes (UTFPR, 2015a). Os docentes da Carreira EBTT vêm sendo aos poucos substituídos por docentes da Carreira do Magistério Superior, isso por conta do processo de transformação do CEFET/PR em Universidade, o que tem impacto na oferta de cursos técnicos, em processo de extinção.

Em sua história, ainda como Escola Técnica Federal do Paraná (ETFPR) ou como Centro Federal de Formação Tecnológica do Paraná (CEFET/PR), a instituição percebeu a necessidade de sistematização de suas práticas avaliativas com vistas às análises sobre a atuação dos profissionais e à qualidade dos resultados dessa atuação.

Nesse contexto, a instituição pesquisada desenvolve, desde 1966, um sistema próprio de avaliação, consolidando ações que envolvem a avaliação de seus docentes e do pessoal técnico-administrativo objetivando às melhorias nos processos de gestão (UTFPR, 2015a).

A partir de 2002, pautado em um enfoque de administração de recursos humanos, a avaliação de desempenho do então CEFET/PR deixa de ser concebida como uma avaliação unilateral e passa a desenvolver uma avaliação multilateral, tendo em vista a necessidade de maior envolvimento dos atores do processo em compromissos com a Universidade e com a educação, direcionando-os para o cumprimento da missão da Instituição.

Em meados de 2009, a instituição já transformada em UTFPR cria o Sistema de Avaliação Institucional (SIAVI). Esse programa informatizado é desenvolvido no âmbito do setor de Gestão de Recursos Humanos e esteve integrado ao Programa de Desenvolvimento Continuado do Servidor, hoje denominado como Diretoria de Gestão da Avaliação Institucional (DIRAV), sendo realizado pela Equipe de Informática.

O referido sistema passa a ser consolidado em 2011, após ajustes necessários à sua implementação. Nesse ínterim tornou-se necessário definir uma forma de gerenciamento que abrangesse todo programa com a filtragem das alterações sugeridas, de forma que nenhuma afetasse negativamente o programa como um todo.

Para atender ao objetivo deste estudo optou-se por analisar as ações que envolvem a Avaliação Institucional, mapeadas em torno da autoavaliação, o que inclui duas categoria de análise, sendo: categoria 1) Instrumentos Avaliativos Internos, definidos em: a) Avaliação do Servidor; b) Avaliação do Docente pelo Discente; c) Avaliação do Desempenho Coletivo de Setores e d) Pesquisa de Clima Organizacional; e categoria 02) Instrumentos Avaliativos 
exigidos em lei, configurados em torno de: a) Relatório de Gestão, b) Relato Institucional, c) Relatório de Autoavaliação e d) Ouvidoria.

\subsection{Instrumentos Avaliativos Internos: demandas originadas na própria IES}

$\mathrm{Na}$ primeira categoria de análise denominada de Instrumentos Avaliativos Internos foram agrupados os processos que envolvem a Avaliação do Servidor, a Avaliação do Docente pelo Discente, a Avaliação do Desempenho Coletivo de Setores e a Pesquisa de Clima Organizacional. Esses processos são analisados considerando-se os procedimentos adotados pela IES pesquisada e as observações dos pesquisadores participantes.

\subsubsection{Avaliação do Servidor}

O processo de Avaliação do Servidor da UTFPR é executado por uma comissão específica, sob a responsabilidade da área de Gestão de Pessoas. A comissão responsável é composta por representantes de diferentes setores e da Comissão Própria de Avaliação (CPA).

A Avaliação do Servidor prevê a etapa da negociação que deve ocorrer entre servidor e a chefia imediata todos os anos, até o mês de março, para que os quesitos a serem avaliados estejam claros para ambas as partes. O sistema é informatizado e 30\% da nota é oriunda da avaliação do docente pelo discente, no caso do servidor professor. Quanto ao servidor administrativo o valor de $30 \%$ é projetado a partir do desempenho coletivo, que é resultante da avaliação do setor.

Conforme situa o Relatório de Autoavaliação Institucional (UTFPR, 2015b) a avaliação de desempenho do servidor se consolida em:

uma avaliação multilateral com o objetivo de atender a necessidade de envolver os servidores em compromissos com a Universidade e com a educação, direcionando os resultados para o cumprimento da missão da Instituição, a partir de um referencial estratégico e metodológico (p. $320)$.

Para atender a tal propósito essa avaliação necessita ser compreendida como um parâmetro para avaliar a Instituição, bem como comportamentos e chefias, além de prospectar, como caráter pedagógico, a constante reavaliação de todos os processos ocorridos na IES.

Os feedbacks que se originam a partir dos processos avaliativos são constantemente analisados pelas comissões específicas e chefias imediatas, as quais têm a responsabilidade de propor ações de ajustes e qualificação das ações desenvolvidas.

A avaliação do servidor quando utilizada adequadamente permite o ajuste de ações e posturas de modo a impactar na melhoria de sua atuação. Para fazer uma boa avaliação é 
Avaliação Institucional em uma universidade pública brasileira multicâmpus: processos e desafios na qualificação da gestão

necessário que o gestor esteja capacitado para tanto. Quanto à equipe de servidores é fundamental que tenham entendimento dos requisitos que devem ser negociados no início do processo. Contudo, na instituição pesquisada nem sempre os gestores receberam capacitação para a utilização adequada desse instrumento e nem sempre as equipes foram preparadas para o processo. Desse modo, ressalta-se a efetiva necessidade de ações institucionais que promovam a discussão em torno dos processos constitutivos da avaliação de desempenho, de modo que essa possa ser compreendida por seus atores e para que sejam obtidos os melhores resultados.

\subsubsection{Avaliação do Docente pelo Discente}

A Avaliação do Docente pelo Discente é gerida por comissão de aplicação sob a responsabilidade da Pró-Reitoria de Graduação e Educação Profissional e ocorre em dois momentos, sendo esses no primeiro e no segundo semestre letivo de cada ano, o que se dá por meio de formulário eletrônico na intranet e internet para que os discentes possam complementálas conforme sua vontade e disponibilidade. Essa avaliação tem peso de 30 pontos na avaliação do professor (em uma escala de 0 a 100), sendo apresentada a partir da média obtida entre os dois semestres.

O Relatório de Gestão da IES indica que:

As avaliações permanecem no banco de dados, sendo processadas pela Diretoria de Gestão de Tecnologia da Informação - DIRGTI. Os resultados são divulgados aos Departamentos Acadêmicos/Coordenações de Curso após o término do semestre letivo, para que os alunos não se sintam inibidos ao avaliar seus atuais professores (UTFPR, 2015a, p. 65).

Nos treze câmpus da UTFPR há dois servidores que fazem parte de duas comissões responsáveis pelo acompanhamento dos processos de Avaliação do Docente pelo Discente, sendo essas: a) Comissão de Aplicação: que inicia seus trabalhos nos primeiros dias do semestre letivo, terminando no último dia do período de avaliação. Nesse período a comissão acompanha diariamente os índices de participação dos discentes nas avaliações por docente, por turma e por curso, detectando os motivos causadores de baixos índices de participação e interagindo para reverter o processo em tempo, desenvolvendo ações de melhoria desses índices, quando abaixo do mínimo esperado; e b) Comissão Pedagógica: cujos trabalhos têm início nos primeiros dias após o término do período avaliativo estendendo-se ao longo do semestre letivo e, em conjunto com os Coordenadores dos Cursos e/ou a pedido dos mesmos, após a análise dos resultados do processo avaliativo, apresenta a devolutiva desses resultados e propõe ações/atividades que visem reparar os pontos frágeis, aprimorar a prática docente e auxiliar o 
corpo docente a entender o processo avaliativo como um mecanismo de auxílio da sua prática pedagógica (UTFPR, 2015b).

Na UTFPR, como a avaliação faz parte da avaliação do servidor, necessariamente os professores têm acesso ao resultado, por meio do SIAVI, cujo acesso é pessoal, mediante login e senhas próprios. Para muitos o feedback é utilizado para a melhoria da prática da atuação docente, uma vez que os estudantes avaliam seus professores a partir de cinco quesitos, configurados em: conteúdo, didática, planejamento, avaliação e relacionamento. Uma das dificuldades nesse processo está relacionada a falta de uma avaliação consciente, por parte de alguns alunos, que nem sempre contribuem com comentários qualificados (uma vez que, além da atribuição de pontos nos quesitos do instrumento pode-se apresentar comentários sobre o desempenho docente), sendo que isso, às vezes, impede a boa utilização dos resultados. Por outro lado, é preciso considerar a necessidade de que os docentes compreendam a avaliação como um instrumento de melhoria de sua prática, pois, nem todos estão preparados para receber o feedback. Os resultados dessa avaliação são analisados de curso para curso e entre câmpus e o entendimento do papel do instrumento pelos atores do processo é fator preponderante para a otimização dos mesmos.

\subsubsection{Avaliação do Desempenho Coletivo de Setores}

A Avaliação do Desempenho Coletivo de Setores ocorre anualmente, no contexto da UTFPR, sendo que essa tem como foco a verificação de como vem ocorrendo a atuação dos setores dentro da instituição, uma vez que oportuniza que os usuários em geral possam expressar suas opiniões a respeito das diferentes áreas e serviços destinados ao atendimento da comunidade externa.

A avaliação de Desempenho Coletivo de Setores, também conhecida como avaliação externa é reconhecida pela IES pesquisada como:

\footnotetext{
uma avaliação multilateral com o objetivo de atender a necessidade de envolver os servidores em compromissos com a Universidade e com a educação, direcionando os resultados para o cumprimento da missão da Instituição, a partir de um referencial estratégico e metodológico (UTFPR, 2015b, p. 320).
}

Essa avaliação deve servir de parâmetro para avaliar a Instituição, comportamentos e chefias, além de ter, como caráter pedagógico, a constante reavaliação (feedback) de todo o processo. Os resultados dos processos avaliativos são analisados pelas comissões específicas e chefias imediatas, as quais têm a responsabilidade de propor ações de melhoria no âmbito da gestão. Cabe ainda, considerar que, por meio dessa avaliação, é possível identificar as fortalezas 
Avaliação Institucional em uma universidade pública brasileira multicâmpus: processos e desafios na qualificação da gestão

e fragilidades de cada setor e a partir dos resultados e assim definir estratégias visando aperfeiçoar os serviços prestados.

A avaliação dos setores pelos usuários externos permite a identificação de oportunidades de melhoria, contudo os resultados são diferenciados de setor para setor, dentro de um mesmo câmpus. No âmbito da UTFPR percebe-se que alguns problemas são estruturais e independem da postura gerencial, como por exemplo, a falta de pessoal, o plano de cargos e salários dos servidores, as contratações por concurso público, os recursos escassos para treinamentos, entre outros. Quanto aos resultados globais destaca-se a importância desse processo de avaliação, sendo necessária a adequada utilização do instrumento, de modo que todos os gestores e equipes aproveitem os resultados da pesquisa para melhorar a atuação, em seus contextos, o que, na IES pesquisada ainda precisa ser mais explorado.

\subsubsection{Pesquisa de Clima Organizacional}

A Pesquisa de Clima Organizacional é um instrumento que, dada a sua característica de levantamento de opiniões centrado em convergências de satisfação e de insatisfação, possibilita atender de modo mais próximo às necessidades das instituições e de seus quadros funcionais. Nessa consulta ocorre "a representação da realidade organizacional consciente, uma vez que retrata o que as pessoas acreditam estar acontecendo em determinado momento na organização enfocada" (BERGAMINI; CODA, 1997, p. 99). Assim, esse tipo de pesquisa visa "tornar claras as percepções dos funcionários sobre temas e itens que, caso apresentem distorções indesejáveis, afetam negativamente o nível de satisfação dos funcionários na situação de trabalho" (p. 99).

A Pesquisa de Clima Organizacional, na IES pesquisada, é realizada, preferencialmente, de acordo com decisão gerencial, de dois em dois anos ou mais, e tem por objetivo obter subsídios para a melhoria da gestão.

O instrumento utilizado na UTFPR é composto por dez dimensões assim delimitadas: 1) Integração Intradepartamental; 2) Relacionamento com superior imediato; 3) Identificação com a empresa; 4) Reconhecimento; 5) Normas e procedimentos; 6) Comunicação e informação; 7) Integração interdepartamental; 8) Filosofia de gestão; 9) Política de treinamento e 10) Estilos de liderança (UTFPR, 2015a).

No ano de 2015 foi realizada a pesquisa de clima organizacional quando ocorreu uma divulgação por meio de reuniões, uso de e-mail, mala direta e visitas aos setores por parte da comissão de aplicação, com o objetivo de sensibilizar os funcionários para a participação da pesquisa. 
A participação nesse processo é espontânea e são respondentes da pesquisa os servidores da instituição. O formulário é disponibilizado no sistema de avaliação e os usuários acessam com a mesma senha de e-mail institucional, no entanto, o sistema não disponibiliza a identificação do respondente, para garantir a liberdade de expressão dos respondentes.

A devolutiva é realizada em reuniões gerenciais e em reuniões públicas, quando todos os servidores são convidados a participar. Nos diversos câmpus da IES pesquisada a reunião é conduzida pelo assessor de avaliação em conjunto com o diretor geral e, na reitoria, com a condução do diretor de avaliação e o reitor.

Ao analisar os procedimentos operacionalizados em torno da Pesquisa de Clima Organizacional constata-se que essa possibilita a identificação de fraquezas e fortalezas que podem contribuir com a melhoria da gestão. Os resultados são diferentes de câmpus para câmpus e cabe a cada gestor fazer a autoavaliação e propor melhorias da sua atuação e da sua equipe.

No que se refere à utilização dos resultados para a melhoria da gestão percebe-se que alguns câmpus os utilizam com maior efetividade e outros encontram dificuldades nesse processo, o que pode estar associado às limitações quanto aos diferentes perfis de gestores.

\subsection{Instrumentos avaliativos externos: demandas originadas no contexto da legislação}

No conjunto de demandas originadas, a partir da macro legislação, para o serviço público a UTFPR adota o Relatório de Gestão, e acresce os instrumentos exigidos pelo SINAES, como o Relatório de Autoavaliação, o Relato Institucional e a Ouvidoria. Nesse tópico, a análise recai sobre esses instrumentos, de modo a compreender a sua operacionalização a partir dos aspectos legais e contextos que se operam na prática na IES pesquisada, despontando a percepção dos pesquisadores participantes.

\subsubsection{Relatório de Gestão}

O Relatório de Gestão é um documento elaborado anualmente e tem por objetivo dar publicidade às ações das IES e também atender aos órgãos de controle externo preconizado pela legislação. Para o ano de 2015 a legislação que orientou a construção desse importante documento esteve circunspecta a atos normativos compreendendo: os termos do Parágrafo Único do Art. 70 da Constituição Federal/1988 e as disposições da Instrução Normativa do Tribunal de Contas da União (IN-TCU) nº 63/2010, Decisão Normativa - TCU n ${ }^{\circ}$ 146, de 30 
Avaliação Institucional em uma universidade pública brasileira multicâmpus: processos e desafios na qualificação da gestão

de setembro de 2015, Portaria da Controladoria-Geral da União (CGU) nº 133, de 18 de janeiro de 2014 e Portaria - TCU n 321 , de 30 de novembro de 2015.

$\mathrm{Na}$ Universidade pesquisada a construção do Relatório é realizada por uma comissão de trabalho, composta por representantes de todas as grandes áreas englobando a reitoria e os treze câmpus. No Relatório de Gestão a UTFPR reforça as proposições do PDI, reafirmando a sua missão, visão e valores, os quais são considerados componentes permanentes e referenciais na definição das políticas, planos e ações da IES, quais sejam:

a) Missão: Desenvolver a educação tecnológica de excelência por meio do ensino, pesquisa e
extensão, interagindo de forma ética, sustentável, produtiva e inovadora com a comunidade
para o avanço do conhecimento e da sociedade; b) Visão: Ser modelo educacional de
desenvolvimento social e referência na área tecnológica; c) Valores: - Ética: gerar e manter a
credibilidade junto à sociedade; - Desenvolvimento Humano: formar o cidadão integrado no
contexto social; - Integração Social: realizar ações interativas com a sociedade para o
desenvolvimento social e tecnológico; - Inovação: efetuar a mudança por meio da postura
empreendedora; - Qualidade e excelência: promover a melhoria contínua dos serviços
oferecidos para a satisfação da sociedade; - Sustentabilidade: assegurar que todas as ações se
observem sustentáveis nas dimensões sociais, ambientais e econômicas (UTFPR, 2015a, p. 53,
com grifos nossos).

A partir do delineamento de sua missão, sua visão e seus valores a UTFPR demonstra o comprometimento com as questões pertinentes ao seu objetivo enquanto instituição superior de ensino público. O vínculo com o desenvolvimento educacional, pelo viés tecnológico, se atrela ao desenvolvimento social e humano, quando a inovação, a qualidade e a excelência mostramse como valores indispensáveis.

O Relatório de Gestão apresenta o acompanhamento do cumprimento das metas institucionais propostas no PDI, bem como demonstra as conquistas e desafios em aspectos quantitativos e qualitativos, resultantes do desenvolvimento das atividades dos macroprocessos finalísticos da Instituição (ensino, pesquisa e extensão) e dos macroprocessos de apoio que envolvem a gestão universitária como um todo (UTFPR, 2015a).

Por ser fruto de uma construção coletiva que envolve os diversos segmentos da instituição o Relatório de Gestão da UTFPR agrega diferentes perspectivas sobre o fazer da universidade, em toda a sua dimensão. Aqui, especialmente, destaca-se a abrangência multicâmpus como um elemento desafiador nesse processo de elaboração de um documento que sintetiza as ações e envolvimentos da IES tanto com a comunidade interna, quanto externa, além do próprio poder público. Essa característica multicâmpus não é um impeditivo para que o processo de construção seja coletivo e o seu resultado qualificado antes, constitui-se numa oportunidade de ampliação do diálogo com os diferentes câmpus, preservando suas peculiaridades e destacando suas características comuns. 


\subsubsection{Relatório de Autoavaliação}

No Relatório de Autoavaliação são apresentadas, de maneira detalhada, as informações em consonância com o PDI e sua construção deve ser vista como um processo de autoconhecimento realizado pela Comissão Própria de Avaliação (CPA) onde deverão estar envolvidos todos os atores que atuam na instituição com o objetivo de analisar as atividades acadêmicas desenvolvidas.

Na definição de um Roteiro para Relatório de Autoavaliação Institucional é apresentada a Nota Técnica INEP/DAES/CONAES nº 065, que conceitua a Autoavaliação como um

[...] processo de indução da qualidade da instituição, que deve aproveitar os resultados das avaliações externas e as informações coletadas a partir do PDI, transformando-o em conhecimento e possibilitando sua apropriação pelos atores envolvidos. (INEP, 2014b, p. 2).

Essa mesma Nota Técnica apresenta a estrutura do relatório, que é composta por cinco eixos que abrangem as dimensões da avaliação institucional anteriormente definidas. Assim, o Eixo 1: Planejamento e Avaliação Institucional abrange a Dimensão 8: Planejamento e Avaliação; o Eixo 2: Desenvolvimento Institucional abarca a Dimensão 1: Missão e Plano de Desenvolvimento Institucional e a Dimensão 3: Responsabilidade Social da Instituição; o Eixo 3: Políticas Acadêmicas inclui a Dimensão 2: Políticas para o Ensino, a Pesquisa e a Extensão, a Dimensão 4: Comunicação com a Sociedade e a Dimensão 9: Política de Atendimento aos Discentes; o Eixo 4: Políticas de Gestão compreende a Dimensão 5: Políticas de Pessoal, a Dimensão 6: Organização e Gestão da Instituição e a Dimensão 10: Sustentabilidade Financeira; o Eixo 5: Infraestrutura Física diz respeito à Dimensão 7: Infraestrutura Física.

O Relatório de Autoavaliação da UTFPR, pela sua composição, permite que se faça o levantamento das informações relevantes da instituição. Como ela tem evoluído e quais os principais pontos de melhoria são elementos indicados pela CPA que, além de utilizar os dados da instituição, também analisa os resultados dos processos avaliativos internos da IES.

Na UTFPR, caracterizada como uma instituição multicâmpus com gestão descentralizada, percebem-se diferenças de atuação em relação aos processos avaliativos e também em relação às devolutivas e implementação de melhorias. Nesse contexto, urge que os resultados expressos detalhadamente no Relatório de Autoavaliação da UTFPR sejam amplamente discutidos, em todos os câmpus, de modo que o reconhecimento das principais questões que envolvem as dimensões constitutivas da IES permita também o reconhecimento das capacidades de ação, do alcance de seus objetivos, de sua missão, visão e valores. 
Avaliação Institucional em uma universidade pública brasileira multicâmpus: processos e desafios na qualificação da gestão

\subsubsection{Relato Institucional}

Com a publicação da Nota Técnica INEP/DAES/CONAES n 062 passou a ser estabelecido o Relato Institucional (RI) como uma inovação do instrumento de avaliação institucional externa para subsidiar ato de credenciamento e recredenciamento das IES e a transformação de organização acadêmica. Esta Nota Técnica define a estrutura do Relato Institucional e busca conceituá-lo, a partir do disposto no documento denominado Instrumento para Avaliação Institucional Externa (modalidade presencial), publicado na Portaria $\mathrm{n}^{\mathbf{0}} 92$ de 31 de janeiro de 2014, como sendo:

um documento que deve ser organizado da seguinte forma: relato avaliativo do PDI; síntese histórica dos resultados dos processos avaliativos internos e externos da IES e síntese histórica do planejamento de ações acadêmico-administrativas decorrentes dos resultados das avaliações (INEP, 2014a, p. 2).

Diferentemente do Relatório de Autoavaliação o Relato Institucional tem por objetivo deixar evidentes os processos de gestão institucional e como eles se desenvolveram a partir das avaliações internas e externas. Ou seja: "o relato deve constar como as avaliações influenciaram ou modificaram o processo de gestão da IES e seus planos de melhoria” (INEP, 2014a, p. 3).

Ainda, segundo a Nota Técnica 062 o RI deve trazer uma análise de como "a estratégia adotada pela Instituição, e as ações e atividades dela decorrentes, atende às orientações estratégicas definidas em seu planejamento, sendo essas: sua missão, sua visão e seus objetivos" (INEP, 2014a, p. 3).

O Relato Institucional, conforme orientações expostas na Nota Técnica 062, deve ter no máximo dez páginas contendo como estrutura os seguintes elementos: 1) Breve histórico da IES; 2) Conceitos obtidos pela IES nas avaliações externas institucionais e de curso; 3 ) Projetos e processos de autoavaliação; 4) Divulgação e análise dos resultados da autoavaliação; 5) Plano de melhorias a partir dos processos avaliativos; 6) Processos de gestão e 7) Demonstração de evolução institucional.

O Relato Institucional é um documento que requer a análise da CPA quanto às ações desenvolvidas pela instituição, a partir do último ato regulatório. No caso da IES pesquisada a visita de avaliação institucional ocorreu em novembro de 2011 e a publicação do recredenciamento ocorreu em 2013, com validade para até 2023. Depois de 2011 a instituição recebeu 73 comissões do INEP com o objetivo de autorizar, reconhecer e recredenciar diversos cursos.

O Relato apresentado pela universidade mostra, de forma resumida, a evolução da instituição nos últimos cinco anos em termos de crescimento de infraestrutura física e de 
pessoal, em termos de cursos ofertados na graduação, na pós-graduação, no número de alunos e nas políticas institucionais.

No contexto da UTFPR o Relato Institucional tem papel importante principalmente na demonstração da análise histórica com indicadores de crescimento qualitativo e quantitativo, uma vez que essa passou por um período de crescimento em função do REUNI. Os indicadores apontados contribuem na percepção o crescimento da instituição em termos de números da graduação, da pós-graduação, da pesquisa, extensão inovação que são qualificados por: Índice Geral de Cursos (IGC), Conceito de curso, ENADE, indicadores de extensão, números de patentes e propriedade intelectual, números de artigos e demais produções bibliográficas.

\subsubsection{Ouvidoria}

A Ouvidoria tem o papel de dar voz ao cidadão, sendo considerada como um instrumento de democratização da participação da comunidade na gestão pública, uma vez que propiciam o efetivo controle social. Para Romão (2012), a Ouvidoria, no contexto de uma instituição pública, visa promover o cidadão à qualidade de coautor das soluções e resultados produzidos no decorrer dos processos de gestão, de modo a integrá-lo "ao trabalho políticoadministrativo de combate às ilegalidades e de implementar melhorias que garantam a efetividade das políticas e dos serviços públicos" (p. 137).

A Instrução Normativa no 1/2014, da Ouvidoria-Geral da União da Controladoria-Geral da União (BRASIL, 2014), em seu art. $1^{\circ}$, parágrafo único, considera que a ouvidoria pública federal é uma instância de controle e participação social responsável pelo tratamento das reclamações, solicitações, denúncias, sugestões e elogios relativos às políticas e aos serviços públicos, prestados sob qualquer forma ou regime, com vistas ao aprimoramento da gestão pública.

A mesma instrução normativa indica, no art. 2, que alguns princípios deverão ser observados, quanto a atuação das ouvidorias, quando se destaca, dentre outros, o da legalidade, da impessoalidade, da finalidade, da motivação, da razoabilidade, da proporcionalidade, da moralidade, da publicidade, do contraditório, da solução pacífica dos conflitos e da prevalência dos direitos humanos. Para o cumprimento desses princípios são inseridas algumas diretrizes assim definidas: I - agir com presteza e imparcialidade; II - colaborar com a integração das ouvidorias; III - zelar pela autonomia das ouvidorias; IV - consolidar a participação social como método de governo; e V - contribuir para a efetividade das políticas e dos serviços públicos (BRASIL, 2014). 
Avaliação Institucional em uma universidade pública brasileira multicâmpus: processos e desafios na qualificação da gestão

A instituição pesquisada tem uma Ouvidoria Geral e treze ouvidorias de câmpus, sendo que possui regulamento próprio aprovado pelo Conselho Universitário. Os processos são analisados e quando é percebida a existência de algum problema nas demandas administrativas acontece o repassasse para o setor responsável para que esse seja solucionado e para que se aproveite a oportunidade para a promoção de melhorias nos processos futuros.

Cabe destacar o relevante papel desempenhado pela Ouvidoria da UTFPR na busca de soluções para as demandas advindas da comunidade, tanto externa quanto interna. Ao agilizar os trâmites de encaminhamentos e de devolutivas ao cidadão, a Ouvidoria se coloca como instrumento com um potencial de mediação significativo, sendo que, a partir de relatórios elaborados semestralmente são disponibilizadas informações que retratam o efetivo alcance nas mediações, oportunizando a reflexão sobre os aspectos que originaram as demandas e tomadas decisões quanto a sua efetiva resolução. Em decorrência das ações articuladas junto à Ouvidoria frequentemente ocorrem ajustes em torno de práticas pedagógicas (em projetos de cursos e ementas de disciplinas), práticas de gestão (processos administrativos, questões comportamentais) e de infraestrutura (reformas e construções, compras de livros e materiais didáticos, entre outros).

\section{Considerações finais}

O processo de avaliação de uma instituição é complexo de se realizar, principalmente quando se trata de uma instituição multicâmpus, pela quantidade de dados que precisam ser catalogados e analisados. O conjunto de instrumentos determinados pelo INEP, para avaliação das IES, demanda esforço significativos para o seu cumprimento, pois depende de comissões que possam fazer as coletas internamente na instituição. As informações levantadas referem-se ao todo da organização e requerem a comparação com os anos anteriores para identificar como a instituição evoluiu nos aspectos avaliados.

Nas tarefas de elaboração de documentos institucionais como o Relatório de Gestão, o Relatório de Autoavaliação e o Relato Institucional também se oportuniza a sistematização das informações acerca dos processos desenvolvidos no contexto da IES. Como instrumentos construídos pela própria instituição, esses são documentos amplos onde devem constar as informações relevantes dos relatórios de avaliação externa e também dos processos avaliativos interno da instituição. Isso traz grande complexidade à análise dos percursos trilhados e, ao mesmo tempo, força a gestão da instituição à reflexão consciente do seu crescimento quantitativo e qualitativo. 
$\mathrm{Na}$ instituição pesquisada pode-se observar a amplitude dos processos que envolvem uma gestão multicâmpus, isto porque as realidades são distintas e ao mesmo tempo faz-se necessário que sejam trabalhados os indicadores padronizados instituídos pelo sistema nacional. Por meio dessa pesquisa documental e participante fica evidente a compreensão dos pesquisadores quanto às dificuldades que se interpõe, em especial, na composição dos relatórios que envolvem os processos avaliativos externos, dada a necessidade de utilização de sistemas independentes de cada área, trazendo informações a partir de diferentes bases de dados. Isso acarreta sobrecarga de trabalho para as equipes técnicas que atuam na sistematização dos instrumentos avaliativos e na análise dos indicadores de desempenho.

Contudo, é necessário evidenciar o amplo cenário que insere a UTFPR como a maior universidade multicâmpus entre as federais do país e uma das dez maiores federais públicas do Brasil. A partir desse panorama torna-se possível o apontamento de algumas considerações importantes, uma vez que as mudanças e inovações fazem parte da sociedade atual e a universidade atua, muitas vezes, como indutora destas inovações por meio de processos que integram as pesquisas, as atividades de ensino e a extensão sendo que na IES pesquisada o caráter tecnológico a distingue e também exige maior interlocução com os distintos setores da sociedade.

Por outro lado, a IES pesquisada vivencia um enorme desafio no sentido de articular um crescimento quantitativo a um crescimento também qualitativo. A UTFPR passou, ao longo da última década, por um significativo processo de ampliação tanto em termos estruturais quanto acadêmicos e também no que se refere aos mecanismos de gestão, dada o intenso processo de expansão proporcionado pelo REUNI. Isso requer que, paralelamente, estejam presentes nos contextos de planejamento e das práticas uma profunda reflexão sobre a qualidade educacional e social almejada em seus documentos orientadores e em suas ações. Esse compromisso se prospecta como a missão da IES, pautada em desenvolver a educação tecnológica de excelência, na articulação entre ensino, pesquisa e extensão, com vistas a uma interação ética, sustentável, produtiva e inovadora com a comunidade que contribua para o avanço do conhecimento e da sociedade.

Toda dinâmica referida neste estudo passa pela definição de indicadores e de processos avaliativos consistentes. A avaliação institucional, na UTFPR, se estrutura a partir dos espaços previstos legalmente, como é o caso da Comissão Própria de Avaliação (CPA) que atua articulada, em todos os câmpus, de modo a perceber e valorizar o caráter mais amplo, situado em torno da área tecnológica, que é o cerne de sua existência e, ao mesmo tempo procura resguardar e reconhecer os elementos que compõem a individualidade de cada câmpus, dadas 
Avaliação Institucional em uma universidade pública brasileira multicâmpus: processos e desafios na qualificação da gestão

as condições culturais, a vocação profissional, as demandas de mercado e necessidades de formação de cada região.

Os processos centrados na avaliação do Servidor, na Avaliação do Docente pelo Discente, na Avaliação do Desempenho Coletivo de Setores e na Pesquisa de Clima Organizacional podem ser percebidos a partir dos progressos experimentados pela IES, em torno da avaliação institucional, o que contribuem significativamente na melhoria da gestão universitária, oportunizando o exercício de democratização ao estimular a participação coletiva no processo de pensar os rumos da universidade e na reorientação de suas práticas.

\section{Referências}

ALMEIDA JÚNIOR, Vicente de Paula. O processo de formação das políticas de avaliação da educação superior no Brasil (1983-1996). Tese (Doutorado) - UNICAMP, Campinas, 2004. Disponível em: <www.bibliotecadigital.unicamp.br/document/?down=vtls000329214>. Acesso em: 02 jul. 2016.

AMORIM, Antônio. Avaliação institucional da universidade. São Paulo: Cortez, 1992.

BERGAMINI, Cecília Whitaker; CODA, Roberto. Psicodinâmica da vida organizacional: motivação e liderança. 2. ed. São Paulo: Atlas, 1997.

BRASIL. Lei no 9.394, de 20 de dezembro de 1996. Estabelece as diretrizes e bases da educação nacional. 1996. Disponível em:

<http://www.planalto.gov.br/ccivil_03/leis/L9394.htm>. Acesso em: 04 jul. 2016.

BRASIL. Lei no 10.861, de 14 de abril de 2004. Institui o Sistema Nacional de Avaliação da Educação Superior - SINAES e dá outras providências. 2004. Disponível em:

<http://www.planalto.gov.br/ccivil_03/_ato2004-2006/2004/lei/110.861.htm>. Acesso em: 02 jul. 2016.

BRASIL. Decreto n 5.773, de 9 de maio de 2006. Dispõe sobre o exercício das funções de regulação, supervisão e avaliação de instituições de educação superior e cursos superiores de graduação e sequenciais no sistema federal de ensino. 2006. Disponível em:

<http://www2.mec.gov.br/sapiens/portarias/dec5773.htm>. Acesso em: 04 jul. 2016.

BRASIL. Controladoria Geral da União. Instrução Normativa no 1, da Ouvidoria-Geral da União da Controladoria-Geral da União. 2014. Disponível em:

<http://www.cgu.gov.br/sobre/legislacao/arquivos/instrucoes-normativas/in-ogu-012014.pdf>. Acesso em Acesso em: 16 jul. 2016.

CALADO, Jorge. O novo paradigma e a inovação científica e pedagógica: novas ideias para a universidade. In: CONCEIÇÃO, Pedro et al (Orgs.). Novas idéias para a universidade. Lisboa: IST Press, 1998.

CARVALHO, Hilda Alberton de; OLIVEIRA, Oséias Santos de; LIMA, Isaura Alberton de. Contribuições da avaliação institucional na qualificação da gestão do ensino superior: o caso da Universidade Tecnológica Federal do Paraná. In: CONGRESSO NACIONAL DE MESTRADOS PROFISSIONAIS EM ADMINISTRAÇÃO PÚBLICA, 1., 2016, Curitiba. Anais.... Curitiba: PROFIAP, 2016. Disponível em: $<$ http://www.profiap.org.br/profiap/eventos/2016/i-congresso-nacional-de-mestrados- 
profissionais-em-administracao-publica/anais-do-congresso/41164.pdf $>$. Acesso em: 12 dez. 2016.

CATANI, Afrânio Mendes; OLIVEIRA, João Ferreira de; DOURADO, Luiz Fernandes. As políticas de gestão e de avaliação acadêmica no contexto da reforma da educação superior. In: MANCEBO, Denise; FÁVERO, Maria de Lourdes de Albuquerque (Orgs.). Universidade: políticas de avaliação e trabalho docente. São Paulo: Cortez, 2004.

CHIZZOTTI, Antonio. Pesquisa qualitativa em ciências humanas e sociais. Petrópolis: Vozes, 2006.

DELFRATE, Célia Regina Cherobim; SANTOS, Sonia Aparecida Gomes dos; TUPICH, Silviane Buss; BRANDALISE, Mary Ângela T. Política multicampi da UEPG: um estudo de caso. In: PEIXE, Blênio César Severo et al. (Org.). Gestão de Políticas Públicas no Estado do Paraná: coletânea de estudos. Curitiba: Progressiva, 2008.

DIAS SOBRINHO, José; BALSAN, Newton Cesar. Avaliação institucional: teorias e experiências. São Paulo: Cortez, 2005.

FIALHO, Nadia Hage. Universidade multicampi. Brasília: Plano Editora, 2005.

GIL, Antonio Carlos. Métodos e técnicas de pesquisa social. 6. ed. São Paulo: Atlas, 2008.

GODOY, Arilda Schmidt. Pesquisa qualitativa: tipos fundamentais. Revista de

Administração de Empresas, São Paulo, v. 35, n. 3, p. 20 -29, maio/jun. 1995. Disponível em: 〈http://www.scielo.br/pdf/rae/v35n3/a04v35n3.pdf>. Acesso em: 06 jul. 2016.

INSTITUTO NACIONAL DE ESTUDOS E PESQUISAS EDUCACIONAIS ANÍSIO TEIXEIRA - INEP. Roteiro para Relatório de Autoavaliação. 2014a. Nota Técnica INEP/DAES/CONAES n065.Disponível em:

<http://download.inep.gov.br/educacao_superior/avaliacao_institucional/nota_tecnica/2014/n ota_tecnica_n65_roteiro_relatorio_de_autoavaliacao_institucional.pdf $>$. Acesso em: 16 jul. 2016.

INSTITUTO NACIONAL DE ESTUDOS E PESQUISAS EDUCACIONAIS ANÍSIO TEIXEIRA - INEP. Define a Estrutura do Relato Institucional. Autoavaliação. 2014b. Nota Técnica INEP/DAES/CONAES n062. Disponível em:

<http://download.inep.gov.br/educacao_superior/avaliacao_institucional/nota_tecnica/2014/n ota_tecnica_n62_relato_institucional.pdf>. Acesso em: 04 jul. 2016.

LAUXEN, Sirlei de Lourdes. Universidade multicampi. In: MOROSINI, Marília Costa (Coord.). Enciclopédia de pedagogia universitária: glossário. Brasília: INEP/MEC, 2006. v. 2. Disponível em: <http://www.publicacoes.inep.gov.br/portal/download/483>. Acesso em: 10 jul. 2016.

LEITE, Denise; TUTIKIAN, Jane; HOLTZ, Norberto (Orgs.). Avaliação e compromisso: Construção e prática da avaliação institucional em uma universidade pública. Porto Alegre: Ed. Universidade/UFRGS, 2000.

MINAYO, Maria Cecília de Souza. O desafio do conhecimento: pesquisa qualitativa em saúde. 12. ed. São Paulo: Hucitec; Abrasco, 2010.

PESSOA, Maria Naiula Monteiro; PETER, Maria da Glória Arrais; COCHRANE, Teresinha Maria Cavalcante. Descrição e análise do sistema de apuração de custos das instituições federais de ensino superior. In: CONGRESSO BRASILEIRO DE CUSTOS, 8., 2001, São Leopoldo, RS. Anais... São Leopoldo, 2001. Disponível em: 
Avaliação Institucional em uma universidade pública brasileira multicâmpus: processos e desafios na qualificação da gestão

<https://anaiscbc.emnuvens.com.br/anais/article/viewFile/2845/2845>. Acesso em: 12 ago. 2016

ROMÃO, José Eduardo. A ouvidoria geral da União e papel das ouvidorias públicas na efetivação do controle social. In: CARDOSO, Antonio Semeraro Rito; LYRA, Rubens Pinto (Orgs.). Modalidades de ouvidoria pública no Brasil: terceira coletânea. João Pessoa: Ed. UFPB, 2012.

SCHALLEMBERGER, Erneldo. Uma Universidade tecnológica multicampi. In: LIMA FILHO, Domingos Leite; TAVARES, Adilson Gil (Orgs.). Universidade tecnológica: concepções, limites e possibilidades. Curitiba: SINDUCEFET-PR, 2006.

SOUZA, Neila Nunes de; SILVA, Mauricio Alves da. A avaliação nas universidades federais brasileiras: um estudo sobre como aparece a Avaliação Institucional na ANDIFES. In:

CONGRESSO IBERO-AMERICANO DE POLÍTICA E ADMINISTRAÇÃO DA EDUCAÇÃO, 4.; CONGRESSO LUSO BRASILEIRO DE POLÍTICA E ADMINISTRAÇÃO DA EDUCAÇÃO, 7., 2014, Porto, Portugal. Anais... Porto, Portugal, 2014. Disponível em: <www.anpae.org.br/IBERO_AMERICANO.../NeilaNunesdeSouza_GT2_integral.pdf>. Acesso em: 19 jun. 2016.

UTFPR. Relatório de gestão: exercício de 2015. Curitiba: UTFPR, 2015a. Disponível em: $<$ http://www.utfpr.edu.br/estruturauniversitaria/couni/portarias/Deliberao01_2016COUNIRelatriodeGesto.pdf >. Acesso em: 19 jun. 2016.

UTFPR. Relatório de Autoavaliação Institucional 2015. Curitiba: UTFPR, 2015b.

Disponível em: <http://www.utfpr.edu.br/estrutura-universitaria/diretorias-degestao/diretoria-de-gestao-da-avaliacao-institucional/cpa-comissao-propria-deavaliacao/2015_relatorio-de-autoavaliacao>. Acesso em: 19 jun. 2016.

YIN, Robert K. Estudo de caso: planejamento e métodos. 3. ed. Porto Alegre: Bookman, 2005.

ZAINKO. Maria Amélia Sabbag. Avaliação da educação superior no Brasil: processo de construção histórica. Avaliação, Campinas; Sorocaba, SP, v. 13, n. 3, p. 827-831, nov. 2008. Disponível em: <http://www.scielo.br/pdf/aval/v13n3/12.pdf>. Acesso em: 20 jul. 2016.

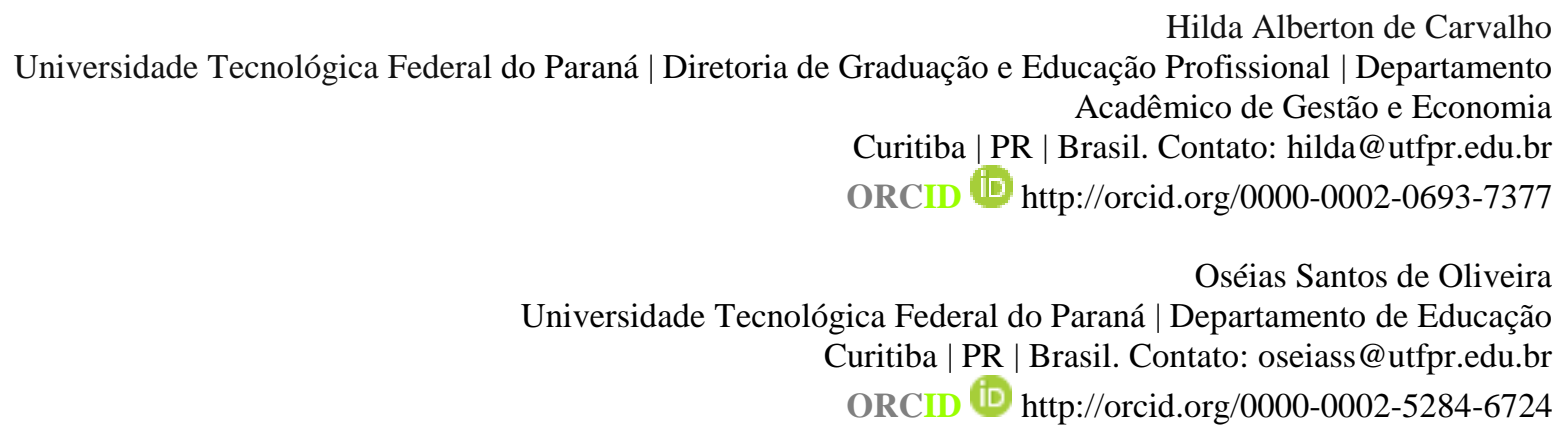

Isaura Alberton de Lima Universidade Tecnológica Federal do Paraná | Programa de Pós-Graduação em Planejamento e Governança Pública Curitiba | PR | Brasil. Contato: alberton@utfpr.edu.br

ORCID (iD http://orcid.org/0000-0001-7450-5579 